\title{
HUBUNGAN ANTARA RELIGIUSITAS DAN MACHIAVELLIAN DENGAN TAX EVASION: RISET BERDASARKAN PERSPEKTIF GENDER
}

\author{
Dekeng Setyo Budiarto ${ }^{\bowtie}$, Yennisa, Fitri Nurmalisa \\ Universitas PGRI Yogyakarta \\ e-mail: dekengsb@upy.ac.id.
}

\begin{abstract}
Tax compliance has long been an issue for governments throughout the world and there is a large and rich research literatur in this field. This study examines the influence religiosity, and machiavellian on the tax evasion based from gender. The sample of this study are 202 accounting students from 8 private university of Special Region of Yogyakarta. The results of the study prove that religiosity has significant influence on tax evasion, while machiavellian has no significant influence on tax evasion. Moreover, there is significant different on tax evasion based from gender. The results are expected for the government to designing policies to prevent tax evasion.
\end{abstract}

Keywords: religiosity, machiavellian, tax evasion, gender

\section{Ringkasan}

Banyak literatur yang telah menguji kepatuhan wajib pajak dan telah lama menjadi masalah bagi pemerintah. Penelitian ini menguji pengaruh religiosity, dan sikap machiavellian terhadap persepsi etis tax evasion berdasarkan gender. Sampel penelitian ini adalah 202 mahasiswa akuntansi dari 8 universitas swasta di Daerah Istimewa Yogyakarta. Hasil penelitian membuktikan bahwa religiosity berpengaruh signifikan terhadap tax evasion, sementara machiavellian tidak berpengaruh signifikan terhadap tax evasion. Selain itu, terdapat perbedaan yang signifikan pada tax evasion berdasarkan gender. Hasil penelitian ini diharapkan memberikan masukan kepada pemerintah untuk membuat kebijakan yang dapat mengurangi penghindaran pajak.

Kata kunci: religiusitas, machiavellian, tax evasion, gender

\section{PENDAHULUAN}

Munculnya kasus-kasus penggelapan pajak yang dilakukan oleh akuntan mengakibatkan berkurangnya kepercayaan masyarakat terhadap profesi akuntan. Kasus penggelapan pajak yang terjadi di Indonesia yang dilakukan oleh pegawai pajak menjadi sorotan dalam pendidikan akuntansi dan menyadarkan bahwa etika sangat penting bagi pendidikan akuntansi (Basri, 2015). Meskipun riset yang meneliti tentang etika perpajakan telah banyak dilakukan Pope \& Mohdali (2010); McGee, Bnek, Yildirim \& Kayikci (2011); Dahrma, Agustin \& 
Kurnia (2016) namun penelitian ini sangat menarik karena: pertama, penggelapan pajak berpengaruh pada belanja pemerintah, kedua, budaya dan perilaku masyarakat dapat mempengaruhi penggelapan pajak, ketiga, aturan pemerintah pada Wajib Pajak menghasilkan interaksi yang kompleks sehingga mempengaruhi moralitas dan perilaku Wajib Pajak (Pope \& Mohdali, 2010).

Tax evasion merupakan perilaku wajib pajak untuk menghindari pajak dengan berbagai usaha termasuk melanggar undangundang perpajakan (Mardiasmo, 2009; Rosianti \& Mangoting, 2015; Dharma et al, 2016). Tax evasion berkaitan dengan perilaku tidak etis karena keputusan seseorang individu untuk mematuhi peraturan perpajakan itu berkaitan dengan moral dan agama. Penggelapan pajak merupakan perilaku tidak etis karena berkaitan dengan psikologi seseorang yang merupakan bagian tidak terpisahkan dari moralitas Wajib Pajak (Feld \& Frey, 2007; Isroah, Hutama, \& Yusita, 2016).

Pada dasarnya sifat Machiavellian merupakan sikap yang negatif yang ada pada seseorang. Sikap negatif yang muncul pada seseorang dapat berupa keinginan melakukan manipulasi, tipu daya, dengan mengabaikan rasa kepercayaan, kehormatan, dan kesopanan. Seorang yang memiliki sikap machiavellian akan cenderung mementingkan kepentingan diri sendiri dan memiliki sikap agresif untuk melaksanakan kepentingannya. Untuk tujuan tertentu seseorang yang memiliki sikap machiavellian akan melakukan segala cara tanpa memperhatikan perasaan, dan hak orang lain. Seorang yang memiliki sikap machiavellian akan cenderung melakukan tindakan tidak etis, melanggar prosedur dan mengabaikan aturan (Christie \& Geis, 1970; Tang \& Chen, 2008).

$$
\text { Religiosity atau religiositas }
$$

berhubungan dengan nilai atau falsafah yang dimiliki seseorang berkaitan dengan agama yang menjadi keyakinannya. Pada dasarnya semua agama memiliki norma yang bertujuan untuk mendorong penganutnya melakukan segala bentuk kebaikan dan melarang segala bentuk kejahatan atau perilaku buruk. Seseorang yang memiliki tingkat religiositas yang tinggi akan lebih mudah menangkal pengaruh buruk. (Anderson \& Tollison, 1992; Basri \& Surya, 2014). Agama merupakan salah satu bentuk keyakinan yang universal dan memiliki pengaruh signifikan terhadap sikap, nilai-nilai, dan perilaku baik ditingkat individu dan masyarakat (Mokhlis, 2009; Fauzan, 2015).

Penelitian ini berbeda dengan penelitian sebelumnya, karena menguji perbedaan persepsi berdasarkan gender. Penelitian ini menarik karena penelitian sebelumnya Tang \& Chen (2008); Westbrook, Steven \& Arendall (2011) menemukan bukti bahwa persepsi etika antara laki-laki dan perempuan berbeda. Selama 3 dekade telah banyak ditemukan bukti empiris berkaitan dengan etika judgment dengan perilaku pada seting dunia kerja. Temuan paling menarik adalah pemahaman etika yang dikaitkan dengan religiosity (Walker, Smither, \& DeBode, 2012).

Tujuan penelitian ini menguji pengaruh religiosity dan machiavellian terhadap tax evasion. Selain itu, penelitian ini juga menguji religiosity, machiavellian dan persepsi tax evasion berdasarkan gender. Hasil penelitian ini diharapkan dapat memberikan masukan kepada perguruan tinggi untuk menyusun kurikulum dengan memasukkan muatan religiosity. Hasil penelitian ini dapat memberikan peluang bagi peneliti selanjutnya untuk mengungkapkan berbagai faktor yang mendorong Wajib Pajak untuk melakukan tax evasion. 
Hubungan antara Religiusitas dan Machiavellian ... (Dekeng Setyo Budiarto,Yennisa, Fitri Nurmalisa)

\section{TINJAUAN PUSTAKA}

\section{Tax Evasion}

Menurut Mardiasmo (2009) tax evasion adalah sebagai usaha yang dilakukan oleh wajib pajak untuk meringankan beban pajak dengan cara melanggar undang-undang. Para wajib pajak mengabaikan ketentuan formal perpajakan yang menjadi kewajibannya, memalsukan dokumen, atau mengisi data dengan tidak lengkap dan tidak benar. Wajib Pajak melakukan berbagai cara menghindari kewajibannya, baik menggunakan cara yang diperbolehkan peraturan undang-undang maupun cara yang melanggar peraturan undang-undang yang berlaku. Penghindaran pajak dengan melanggar dan menentang peraturan undang-undang yang berlaku disebut Tax Evasion (Dharma, 2016).

Tax evasion adalah tindakan yang melanggar undang-undang, penggelapan pajak ini dilakukan dengan menggunakan cara yang tidak legal karena Wajib Pajak akan mengabaikan ketentuan formal perpajakan yang menjadi kewajibannya dengan memalsukan dokumen, atau mengisi data dengan tidak lengkap dan tidak benar (Kurniawati \& Toly, 2015). Menurut Zain (2008: 78) penggelapan pajak terjadi karena Wajib Pajak melakukan hal-hal berikut:

a. Tidak memenuhi pengisian Surat Pemberitahuan tepat waktu.

b. Tidak memenuhi pelaporan penghasilan dan pengurangannya secara lengkap dan benar.

c. Tidak dapat memenuhi pembayaran pajak tepat waktu.

d. Tidak memenuhi kewajiban memelihara pembukuan.

e. Tidak memenuhi kewajiban menyetorkan pajak penghasilan yang dipotong dan dipungut.

f. Tidak memenuhi kewajiban membayar taksiran pajak terutang.

g. Tidak memenuhi permintaan fiskus akan informasi pihak ketiga. h. Melakukan penyuapan terhadap aparat perpajakan dan atau tindakan intimidasi lainnya.

\section{Religiusitas}

Menurut Mc Daniel \& Burnett, (1990); Rosianti (2014) religiosity adalah sebuah kepercayaan kepada Tuhan dengan berkomitmen untuk mengikuti prnsip-prinsip yang telah ditetapkan Tuhan. Religiusitas merupakan nilai-nilai agama yang dianut oleh seseorang. Semua agama umumnya memiliki tujuan sama dalam mengontrol perilaku yang baik dan menghambat perilaku buruk (Basri, 2015). Religiusitas dapat didefinisikan sebagai suatu sistem yang terintegrasi dari keyakinan, gaya hidup, aktivitas ritual dan institusi yang memberikan makna dalam kehidupan manusia dan mengarahkan manusia pada nilai-nilai yang suci (Glock \& Stark, 1965).

Religiusitas memiliki dua dimensi yang berbeda, yaitu religiusitas ekstrinsik dan religiusitas intrinsik. Religiusitas ekstrinsik mengacu pada motivasi seserorang dalam berperilaku religius. Religiusitas ekstrinsik merupakan pendekatan seseorang dalam beragama dan mencerminkan motivasi seseorang untuk persetujuan sosial. Sebaliknya, religusitas intrinsik mengacu pada motivasi yang didasarkan pada inheren dan tradisi keagamaan itu sendiri. Religiusitas intrinsik menunjukkan adanya komitmen dan keterlibatan religiusitas untuk tujuan rohani yang lebih melekat dalam berkomitmen dengan prinsip agama (Allport, 1950; Vitell et al, 2011; Singhapakdi et al, 2013). Glock \& Stark merumuskan religiusitas sebagai komitmen yang berhubungan dengan agama atau keyakinan iman yang dapat dilihat melalui aktivitas atau perilaku individu yang bersangkutan dengan agama atau keyakinan iman yang dianut. Pengukuran religiusitas menurut Glock \& Stark (1965) dapat dikelompokkan dalam beberapa aspek sebagai berikut: 
a. Religiusitas berdasarkan praktek tingkatan sejauh mana seseorang mengerjakan kewajiban ritual di dalam agama, seperti sembahyang, zakat, puasa dan sebagainya.

b. Religiusitas berdasarkan keyakinan yaitu sejauh mana seseorang menerima hal-hal yang dogmatik di dalam ajaran agamanya. Misalnya kepercayaan tentang adanya Tuhan, Malaikat, Kitab-Kitab Suci dan Nabi.

c. Religiusitas berdasarkan pengetahuan yaitu seberapa jauh seseorang mengetahui tentang ajaran agamanya, hal ini berhubungan dengan aktivitas seseorang untuk mengetahui ajaranajaran dalam agamanya.

d. Religiusitas berdasarkan perasaan yaitu terdiri dari perasaan-perasaan dan pengalaman-pengalaman keagamaan yang pernah dirasakan dan dialami. Misalnya seseorang merasa dekat dengan Tuhan, seseorang merasa takut berbuat dosa, seseorang merasa doanya dikabulkan Tuhan

e. Religiusitas berdasarkan efek yaitu mengukur sejauh mana perilaku seseorang dimotivasi oleh ajaran agamanya di dalam kehidupannya.

\section{Machiavellian}

Machiavellian didasarkan pada kebijaksanaan, manipulasi, eksploitasi, tipu daya, tanpa kepercayaan, kebijakan tradisional, kehormatan, dan kesopanan. Seorang machiavellian cenderung mementingkan kepentingan diri sendiri, manipulatif, dan juga agresif untuk mencapai tujuan tanpa memperhatikan perasaan, hak, dan kebutuhan orang lain. (Christie dan Geis, 1970; Wilson et al,1996; Tang \& Chen, 2008). Machiavellianism dapat didefinisikan sebagai strategi perilaku sosial yang melibatkan memanipulasi orang lain untuk keuntungan pribadi, dan sering bertentangan dengan kepentingan yang lain. Christie \& Geis (1970) machiavellianism cenderung memiliki karakteristik sebagai berikut: relatif kurang berpengaruh dalam hubungan interpersonal, kurang perhatian dengan moralitas konvensional, gross psychopathology, dan komitmen ideologis yang rendah (Tang \& Chen, 2008). Shafer dan Simmons (2008) mengidentifikasi tiga hal yang mendasari machiavellianisme, yaitu:

a. Advokasi pada taktik manipulatif seperti tipu daya atau kebohongan;

b. Pandangan atas manusia yang tak menyenangkan, yaitu lemah, pengecut, dan mudah dimanipulasi; dan

c. Kurangnya perhatian dengan moralitas konvensional.

\section{Hubungan antara religiusitas dengan tax evasion}

Religiosity atau religiusitas diartikan sebagai seberapa jauh pengetahuan, seberapa kokoh keyakinan, seberapa rutin dalam melaksanakan ibadah dan kaidah dan seberapa besar dalam penghayatan atas agama yang dianutnya yang dapat berpengaruh terhadap perilaku etis seseorang (Dharma et al, 2016). Penelitian Basri (2015); Dharma et al (2016) menunjukkan bahwa religiusitas tidak berpengaruh terhadap tax evasion. Penelitian Conroy \& Emerson (2004); Walker et al (2012) menunjukkan hubungan yang lemah antara religiusitas dengan pesepsi etis. Namun temuan Longenecker, McKinney \& Moore (2004); Walker et al (2012); Wati \& Sudibyo (2016) membuktikan bahwa religiusitas berpengaruh terhadap terhadap persepsi etis. Semakin rendah tingkat religiusitas seseorang akan semakin besar kemungkinan melakukan tax evasion. Berdasarkan hasil beberapa riset diatas maka diajukan hipotesis sebagai berikut:

$\mathrm{H}_{1}$ : Religiusitas berpengaruh negatif terhadap tax evasion 


\section{Hubungan antara Machiavellian dengan tax evasion}

Machiavellianism dapat didefinisikan sebagai strategi perilaku sosial yang melibatkan seseorang untuk memanipulasi orang lain demi keuntungan pribadi, dan sering bertentangan dengan kepentingan umum. Riset sebelumnya menjelaskan bahwa machiavellianism cenderung memiliki karakteristik sebagai berikut: hubungan interpersonal yang kurang baik, kurang perhatian, moralitas yang rendah, memiliki sifat gross psychopathology, dan komitmen ideologis yang (Christie \& Geis, 1970; Li-Ping Tang, Chen, \& Sutarso, 2008). Seseorang yang memiliki sifat machiavellian tinggi memungkinkan untuk berperilaku tidak etis (Richmond, 2001; Rindayati \& Budiarto, 2017). Yuliana \& Cahyonowati (2012); Aziz \& Taman (2015) menyatakan perilaku machiavellian berpengaruh terhadap persepsi etis. Semakin tinggi tingkat machiavellian seseorang maka semakin besar kemungkinan melakukan tax evasion. Berdasarkan hasil beberapa riset diatas maka diajukan hipotesis sebagai berikut:

$\mathrm{H}_{2}$ : Machiavellian berpengaruh positif terhadap tax evasion

\section{Analisis berdasarkan gender}

Gender adalah suatu konsep analisis yang digunakan untuk mengidentifikasi perbedaan laki-laki dan perempuan dilihat dari sudut non-biologis, yaitu dari aspek sosial, budaya, maupun psikologis (Muthmainah, 2006; Mulyani (2015). Persepsi mengenai etis atau tidaknya perilaku antara laki-laki dan perempuan memiliki perbedaan. Perilaku etis Laki-laki cenderung rendah dibanding perempuan. Hal ini disebabkan karena kebanyakan laki-laki lebih berani mengambil risiko dan melakukan segala cara untuk mencapai keinginannya. Laki-laki Muslim, Yahudi dan Hindu lebih religius dibandingkan dengan perempuan, namun perempuan Kristiani lebih religius dibandigkan laki-laki karena perbedaan tradisi (Basri, 2015).

Seseorang yang memiliki tingkat machiavellian tinggi akan melakukan segala cara untuk memenuhi kebutuhan, meskipun tidak sesuai dengan etika. Laki-laki dilihat dari tingkat machiavellian cenderung berambisi dengan tingkat manipulasi yang tinggi untuk mencapai apa yang diinginkan seperti posisi, gelar, atau otoritas (Yelshinta \& Fuad, 2013).

Sebuah survei terhadap mahasiswa bisnis di Jerman menemukan bahwa responden sangat menentang penghindaran pajak, namun tidak ditemukan dengan pasti responden laki-laki atau perempuan yang lebih menentang penghindaran pajak (McGee \& Preobragenskaya, 2006). Pendekatan struktural, menyatakan bahwa perbedaan laki-laki dan perempuan disebabkan oleh sosialisasi awal terhadap pekerjaan dan kebutuhan lain. Menyikapi perilaku penggelapan pajak maka lakilaki dan perempuan mempunyai jawaban yang berbeda. Kasus penggelapan pajak, jika dilihat sebagian besar yang melakukan tindakan yaitu laki-laki. Laki-laki lebih banyak melakukan penghindaran pajak daripada perempuan (Dharma et al, 2016).

$\mathrm{H}_{3 \mathrm{a}}$ : Terdapat perbedaan tingkat religiusitas berdasarakan gender

$\mathrm{H}_{3 \mathrm{~b}}$ : Terdapat perbedaan tingkat machiavellian berdasarkan gender

$\mathrm{H}_{3 \mathrm{c}}$ : Terdapat perbedaan tingkat tax evasion berdasarkan gender

\section{METODE PENELITIAN}

Penelitian ini menggunakan pendekatan akuntansi positif yang dibangun berdasarkan pada asumsidan realitas sosial termasukperilaku manusia. Penelitian ini merupakan penelitian kuantitatif yang menggunakan data primer yang diperoleh melalui penyebaran kuesioner 
berupa butir pertanyaan untuk variabel persepsi etis tax evasion, love of money dan religiusitas. Penelitian kuantitatif merupakan penelitian yang termasuk dalam pendekatan positivisme (Sharma \& Bhagwat, 2006).

Sampel penelitian ini adalah 202 mahasiswa akuntansi dari 8 perguruan tinggi swasta di Daerah Istimewa Yogyakarta. Data dikumpulkan dengan menyebarkan kuesioner kepada mahasiswa akuntansi dengan teknik purposive sampling dengan kriteria tertentu. Kriteria yang dimaksud adalah pertama: responden merupakan mahasiswa jurusan akuntansi, kedua: responden merupakan mahasiswa dari perguruan tinggi yang telah terakreditasi di Yogyakarta. Ukuran sampel yang layak dalam penelitian adalah 30 sampai dengan 500, namun penelitian ini menggunakan analisis multivariate maka jumlah anggota sampel minimal 10 kali dari jumlah variabel yang diteliti. Variabel independen dan variabel dependen berjumlah 3 maka jumlah anggota sampel 30 (10x3) (Sekaran \& Bougie, 2016). Kuesioner yang disebar adalah 250, kuesioner yang kembali adalah 224 sedangkan yang dapat digunakan sebagai analisis adalah 202. Hasil penyebaran kuesioner menunjukkan bahwa 99 kuesioner merupakan mahasiswa dari perguruan tinggi swasta terakreditasi A, 81 kuesioner terakeditasi B sedangkan sisanya 44 kuesioner terakreditasi C. Hasil diskripsi responden ditunjukkan pada (Tabel 1).

\section{Tax Evasion}

Variabel dependen penelitian ini adalah tax evasion yaitu persepsi dan etika seseorang terhadap penghindaran pajak. Seseorang dapat melakukan penghindaran pajak karena adanya perasaan tidak adil sehingga penghindaran pajak merupakan hal biasa. Variabel tax evasion diukur menggunakan pandangan pertama yaitu: pertama tax evasion tidak etis, kedua tax evasion kadang-kadang etis, dan ketiga tax evasion etis (Basri, 2015). Tax evasion diukur menggunakan 15 item pertanyaan diukur dengn skala likert dengan poin 1 (sangat tidak setuju) sampai dengan 7 (sangat setuju).

\section{Gender}

Variabel gender penelitian ini hanya digunakan untuk menguji apakah terdapat perbedaan persepsi pada variabel religiusitas, machiavellian, dan tax evasion berdasarkan perbedaan jenis kelamin. Gender diukur menggunakan variabel dummy dimana 1 untuk laki-laki dan 0 untuk perempuan (Dharma et al, 2016).

\section{Religiusitas}

Religiusitas pada penelitian ini merupakan nilai-nilai agama yang dianut seseorang, seseorang yang memiliki tingkat religiusitas tinggi akan memiliki etika yang baik. Religiusitas diukur menggunakan 20 item pertanyaan yang diadopsi dari penelitian (Basri, 2015). Pertanyaan dibagi menjadi 2 yaitu religiusitas intrinsik 12 item pertanyaan dan religiusitas ekstrinsik 8 item pertanyaan, diukur menggunakan skala likert dengan poin 1 (sangat tidak setuju) sampai dengan 7 (sangat setuju).

Tabel 1. Deskripsi Responden

\begin{tabular}{llccccc}
\hline \multirow{2}{*}{ No } & \multirow{2}{*}{ Gender } & \multicolumn{3}{c}{ Akreditasi } & \multirow{2}{*}{ Jumlah } & Prosentase \\
\cline { 3 - 6 } & & A & B & C & \\
\hline 1 & Laki-laki & 41 & 10 & 10 & 61 & $30,2 \%$ \\
\hline 2 & Perempuan & 49 & 63 & 29 & 141 & $69,8 \%$ \\
\hline
\end{tabular}

Sumber: data primer diolah tahun 2017 


\section{Machiavellian}

Machaivellian diukur menggunakan 4 item pertanyaan dengan 2 indikator yaitu tactics dan human nature (Tang \& Chen, 2008). Pertanyaan diukur menggunakan skala likert poin 1 (sangat tidak setuju) samapi dengan 7 (sangat setuju).

\section{HASIL DAN PEMBAHASAN}

\section{Pengujian Instrumen}

Pengujian instrumen pada penelitian ini menggunakan uji validitas dan uji reliabilitas.
Instrumen yang valid berarti alat ukur yang digunakan untuk mendapatkan data (mengukur) valid. Valid berarti instrumen tersebut dapat digunakan untuk mengukur apa yang seharusnya diukur (Sugiono, 2010:121). Hasil uji validitas menunjukkan seluruh variabel penelitian yaitu religiusitas, machavellian dan tax evasion adalah valid dengan pearson correlation $<0,05$.

Tabel 2. Hasil Uji Validitas Variabel Tax Evasion

\begin{tabular}{|c|c|c|}
\hline No & Instrumen & $\begin{array}{c}\text { Pearson } \\
\text { correlation }\end{array}$ \\
\hline 1 & Penggelapan pajak etis jika tingkat pajak terlalu tinggi & $0,554 * *$ \\
\hline 2 & $\begin{array}{l}\text { Penggelapan pajak etis jika tingkat pajak tidak terlalu tinggi karena pemerintah ti- } \\
\text { dak berhak mengambil lebih banyak dari yang saya dapat }\end{array}$ & $0,560 * *$ \\
\hline 3 & Penggelapan pajak etis jika sistem pajak tidak adil & $0,626 * *$ \\
\hline 4 & Penggelapan pajak etis jika sebagian besar uang yang dikumpulkan terbuang & $0,578 * *$ \\
\hline 5 & $\begin{array}{l}\text { Penggelapan pajak etis jika sebagian besar uang yang dikumpulkan dihabiskan den- } \\
\text { gan bijaksana }\end{array}$ & $0,634 * *$ \\
\hline 6 & $\begin{array}{l}\text { Penggelapan pajak etis jika sebagian besar uang yang dikumpulkan dihabiskan un- } \\
\text { tuk proyek-proyek yang secara moral saya setuju }\end{array}$ & $0,618 * *$ \\
\hline 7 & $\begin{array}{l}\text { Penggelapan pajak etis jika sebagian besar uang yang dikumpulkan dihabiskan un- } \\
\text { tuk proyek-proyek yang layak }\end{array}$ & $0,640 * *$ \\
\hline 8 & $\begin{array}{l}\text { Penggelapan pajak etis jika sebagian besar uang yang dikumpulkan dihabiskan un- } \\
\text { tuk proyek-proyek yang tidak menguntungkan saya }\end{array}$ & $0,515 * *$ \\
\hline 9 & $\begin{array}{l}\text { Penggelapan pajak etis jika sebagian besar uang yang dikumpulkan dihabiskan un- } \\
\text { tuk proyek-proyek yang menguntungkan saya }\end{array}$ & $0,657 * *$ \\
\hline 10 & Penggelapan pajak etis jika semua orang melakukannya & $0,511 * *$ \\
\hline 11 & $\begin{array}{l}\text { Penggelapan pajak etis jika sebagian besar uang yang terkumpul di kantongi politisi } \\
\text { korup atau keluarga dan teman-teman mereka }\end{array}$ & $0,533 * *$ \\
\hline 12 & Penggelapan pajak etis jika kemungkinan tertangkap aparat hukum rendah & $0,546 * *$ \\
\hline 13 & $\begin{array}{l}\text { Penggelapan pajak etis jika sebagian hasil digunakan untuk mendukung sebuah } \\
\text { negara yang tidak memiliki hubungan diplomatik dengan Negara kita }\end{array}$ & $0,660 * *$ \\
\hline 14 & Penggelapan pajak etis jika saya tidak mampu untuk membayar & $0,533 * *$ \\
\hline 15 & $\begin{array}{l}\text { Penggelapan pajak etis bahkan jika saya membayar lebih sedikit, sedangkan orang } \\
\text { lain harus membayar lebih banyak }\end{array}$ & $0,519 * *$ \\
\hline
\end{tabular}


Tabel 3. Hasil Uji Validitas Variabel Religiusitas Intrinsik

\begin{tabular}{llc}
\hline No & \multicolumn{1}{c}{ Instrumen } & $\begin{array}{c}\text { Pearson } \\
\text { correlation }\end{array}$ \\
\hline 1 & $\begin{array}{l}\text { Penting bagi saya menghabiskan waktu untuk menyendiri merenung memperdalam } \\
\text { ilmu agama }\end{array}$ & $0,508^{* *}$ \\
\hline 2 & $\begin{array}{l}\text { Jika tidak ada kondisi darurat yang menghalangi saya ketempat ibadah, saya akan } \\
\text { pergi ketempat ibadah }\end{array}$ & $0,522^{* *}$ \\
\hline 3 & Saya berusaha membawa nilai-nilai agama ke dalam kehidupan saya & $0,695^{* *}$ \\
\hline 4 & Saya mencurahkan seluruh perasaan saya ketika berdoa & $0,588^{* *}$ \\
\hline 5 & Saya merasa Tuhan sering hadir dalam hidup saya & $0,567^{* *}$ \\
\hline 6 & $\begin{array}{l}\text { Saya lebih memilih untuk bergabung di grup pengajian dibandingkan kelompok } \\
\text { sosial }\end{array}$ & $0,437^{* *}$ \\
\hline 7 & Saya menggunakan pendekatan agama dalam menjalankan kehidupan & $0,554^{* *}$ \\
\hline 8 & Agama sangat penting, karena agama menjawab semua pertanyaan hidup & $0,562^{* *}$ \\
\hline 12 & $\begin{array}{l}\text { Meskipun saya yakin dengan agama saya, saya merasa ada banyak hal lain yang } \\
\text { lebih penting dalam hidup }\end{array}$ & $0,262^{* *}$ \\
\hline
\end{tabular}

Ket: $* *$ signifikansi $<1 \%$, sumber: data primer diolah tahun 2017

Tabel 4. Hasil Uji Validitas Variabel Religuisitas Ekstrinsik

\begin{tabular}{llc}
\hline No & \multicolumn{1}{c}{ Instrumen } & $\begin{array}{c}\text { Pearson } \\
\text { correlation }\end{array}$ \\
\hline 1 & Agama menawarkan rasa nyaman saat sedih atau ditimpa musibah & $0,654^{* *}$ \\
\hline 2 & Saya berdoa terutama karena saya telah diajarkan untuk berdoa & $0,594^{* *}$ \\
\hline 3 & $\begin{array}{l}\text { Meskipun saya orang religius saya menolak memasukkan pertimbangan agama } \\
\text { dalam mempengaruhi urusan saya }\end{array}$ & $0,142^{*}$ \\
\hline 4 & $\begin{array}{l}\text { Pergi ke tempat ibadah adalah sebuah kegiatan sosial yang menyenangkan, inilah } \\
\text { alasan terpenting dari agama }\end{array}$ & $0,585^{* *}$ \\
\hline 5 & $\begin{array}{l}\text { Menjadikan tempat ibadah sebagai tempat yang cocok untuk aktivitas sosial, itulah } \\
\text { manfaat utama dari agama }\end{array}$ & $0,477^{* *}$ \\
\hline 6 & $\begin{array}{l}\text { Adakalanya saya merasa perlu mempertimbangkan keyakinan agama saya untuk me- } \\
\text { lindungi kesejahteraan sosial dan ekonomi saya }\end{array}$ & $0,294^{* *}$ \\
\hline 7 & $\begin{array}{l}\text { Salah satu alasan untuk saya menjadi anggota keagamaan adalah bahwa keanggotaan } \\
\text { tersebut membantu untuk membentuk seseorang di masyarakat }\end{array}$ & $0,576^{* *}$ \\
\hline 8 & \begin{tabular}{l} 
Tujuan beribadah adalah untuk hidup bahagia dan damai \\
\hline Ket:
\end{tabular} & $0,593^{* *}$ \\
\hline
\end{tabular}

Ket: ** signifikansi $<1 \%, *$ signifikansi $<5 \%$ sumber: data primer diolah tahun 2017 
Hubungan antara Religiusitas dan Machiavellian ... (Dekeng Setyo Budiarto,Yennisa, Fitri Nurmalisa)

Tabel 5. Hasil Uji Validitas Variabel Machiavellian

\begin{tabular}{clc}
\hline No & \multicolumn{1}{c}{ Instrumen } & $\begin{array}{c}\text { Pearson } \\
\text { correlation }\end{array}$ \\
\hline 1 & $\begin{array}{l}\text { Jalan yang paling baik untuk memahami seseorang adalah berkata } \\
\text { kepadanya apa yang mereka inginkan untuk didengar }\end{array}$ & $0,557^{* *}$ \\
\hline 2 & Sangat sulit untuk maju tanpa mengikuti prosedur formal & $0,646^{* *}$ \\
\hline 3 & Akan selalu merahasiakan segala sesuatu kepada siapapun & $0,722^{* *}$ \\
\hline 4 & $\begin{array}{l}\text { Hal yang paling aman adalah mengasumsikan bahwa semua orang itu } \\
\text { akan berperilaku kurang baik jika diberikan kesempatan }\end{array}$ & $0,708^{* *}$ \\
\hline
\end{tabular}

Ket: ** signifikansi $<1 \%$, sumber: data primer diolah tahun 2017

Tabel 6. Hasil Uji Reliabilitas

\begin{tabular}{cccc}
\hline Variabel & Item & Cronbach Alpha & Keterangan \\
\hline Religiusitas & $\mathrm{X} 1-\mathrm{X} 20$ & 0,844 & Reliabel \\
Machiavellian & $\mathrm{X} 21-\mathrm{X} 24$ & 0,567 & Reliabel \\
Tax Evasion & $\mathrm{Y} 1-\mathrm{Y} 15$ & 0,859 & Reliabel \\
\hline
\end{tabular}

Sumber: data primer diolah tahun 2017

Tabel 7. Hasil Uji One-Sample Kolmogorov-Smirnov Test

\begin{tabular}{ccc}
\hline Variabel & P Value & Keterangan \\
\hline Religiusitas & 0,523 & Normal \\
Machiavellian & 0,812 & Normal \\
Tax evasion & 0,724 & Normal \\
\hline
\end{tabular}

Sumber: data primer diolah tahun 2017

Uji normalitas bertujuan untuk menguji apakah data yang digunakan pada penelitian terdistribusi normal karena data yang tidak terdistribusi normal maka uji statistik menjadi tidak valid untuk jumlah sampel kecil. Uji normalitas data dilakukan dengan uji kolmogorov-smirnov untuk mempermudah melakukan perhitungan secara statistik. Data berdistribusi normal jika Asymp Sig (2-tailed) hasil perhitungan kolmogorov-smirnov > 0,05 (Ghozali, 2011: 160). Apabila hasil dari pengujian normalitas data terbukti bahwa data terdistribusi secara normal maka selanjutnya dilakukan uji independent sample t-test tetapi apabila data tidak terdistribusi normal menggunakan uji mann whitney (Sugiono, 2010:158). Hasil pengujian normalitas data (Tabel 6) menunjukkan bahwa semua data pada variabel yang diuji terdistribusi normal.
Instrumen yang reliabel adalah instrumen yang digunakan beberapa kali untuk mengukur objek yang sama, akan menghasilkan data yang sama (Sugiono, 2010:130). Reliabilitas adalah ketetapan suatu tes yang dapat diteskan pada objek yang sama untuk mengetahui ketetapan ini, pada dasarnya melihat kesejajaran hasil. Instrumen yang memiliki nilai 0,4 sampai 0,6 dikatakan cukup reliabel, instrumen yang memiliki nilai lebih dari 0,6 memiliki reliabilitas yang tinggi (Arikunto, 2013:89). Hasil pengujian reliabilitas pada Tabel 6 menunjukkan seluruh variabel penelitian memiliki nilai Cronbach Alpha lebih dari 0,5 (reliabel).

Uji multikolonieritas bertujuan untuk menguji apakah model regresi ditemukan adanya korelasi anatar variabel bebas 
(independen). Multikolonieritas dapat dilihat dari (1) nilai tolerance dan (2) Variance Inflation Factor (VIF). Kedua ukuran ini menunjukkan setiap variabel independen manakah yang dijelaskan oleh variabel independen lainnya. Tolerance mengukur variabilitas variabel independen yang terpilih yang tidak dijelaskan oleh variabel independen lainnya. Apabila nilai tolerance $>$ dari $10 \%$ dan nilai VIF $<10$ maka tidak terjadi multikoleniaritas (Ghozali, 2011:105). Hasil pengujian multikoleniaritas (Tabel 8) menunjukkan bahwa tidak terjadi multikoleniaritas antar variabel.

\section{Pengujian Hipotesis dan Pembahasan}

Pengujian hipotesis 1 dan hipotesis 2 dilakukan untuk menguji pengaruh religiusitas, machiavellian terhadap tax evasion (Tabel 8). Pengujian hipotesis 3 dilakukan untuk menguji apakah terdapat perbedaan antara religiusitas, machiavellian, dan persepsi etis tax evasion berdasarkan gender (Tabel 10).

Berdasarkan Tabel 8 dapat dijelaskan bahwa religiusitas berpengaruh terhadap tax evasion dengan p value $>0,05(0,007)$. Hasil penelitian mendukung temuan sebelumnya yaitu semakin tinggi religiusitas maka seseorang akan cenderung memiliki tingkat kepatuhan pajak yang tinggi (Utama \& Wahyudi, 2016). Hasil penelitian menunjukkan moralitas Wajib Pajak akan berpengaruh terhadap kepatuhan Wajib Pajak. Bahkan seseorang akan menggunakan integritas moralnya melebihi semua hal meskipun harus mengeluarkan biaya yang tidak sedikit (Pope \& Mohdali, 2010). Hasil penelitian ini memberi masukan kepada pihak pemerintah karena Wajib Pajak akan patuh jika pelayanan yang dirasakan sesuai dengan yang dibayarkan (Torgler, Demir, Macintyre, \& Schaffner, 2008).

Tabel 8 menunjukkan bahwa machiavellian tidak berpengaruh terhadap tax evasion dengan $\mathrm{p}$ value $<0,05(0,458)$. Hasil penelitian ini mendukung penelitian (Aziz \& Taman, 2015) yang menunjukkan machiavellian tidak berpengaruh terhadap persepsi etis. Hasil riset menunjukkan bahwa, mahasiswa tidak memiliki sifat machiavellian, contohnya jawaban pertanyaan tentang kemauan memahami seseorang diperoleh ratarata 5,3 artinya mahasiswa memiliki sikap yang baik. Jawaban pertanyaan "sangat sulit untuk maju tanpa mengikuti prosedur formal" dengan rata-rata jawaban 4,8 artinya mahasiswa tidak percaya bahwa untuk sukses seseorang tidak harus melanggar prosedur formal.

Tabel 8. Hasil Uji t (Hipotesis 1 dan 2)

\begin{tabular}{lcccc}
\hline \multicolumn{1}{c}{ Variabel } & B & Tolerance & VIF & P Value \\
\hline Religiusitas & $-0,298$ & 0,866 & 1,155 & $0,007^{*}$ \\
Machiavellian & 0,057 & 0,866 & 1,155 & 0,458 \\
\hline F Hitung $=3,794$ & & & $0,024^{*}$ \\
Adjusted $R$ Square $=0,027$ & & & \\
\hline Ket: $*$ signifikansi $<5 \%$, sumber: data primer diolah tahun 2017 & &
\end{tabular}

Tabel 9. Hasil Pengujian Hipotesis

\begin{tabular}{lc}
\hline \multicolumn{1}{c}{ Hipotesis } & Hasil \\
\hline $\mathrm{H}_{1}:$ Religiusitas berpengaruh negatif terhadap tax evasion & Diterima \\
$\mathrm{H}_{2}:$ Machiavellian berpengaruh positif terhadap tax evasion & Ditolak \\
\hline
\end{tabular}


Hubungan antara Religiusitas dan Machiavellian ... (Dekeng Setyo Budiarto,Yennisa, Fitri Nurmalisa)

Tabel 10. Hasil Uji Independent-Samples t test (Hipotesis 3)

\begin{tabular}{|c|c|c|c|c|c|c|}
\hline \multirow[t]{2}{*}{ Variabel } & \multicolumn{2}{|c|}{ Laki-laki } & \multicolumn{2}{|c|}{ Perempuan } & \multirow{2}{*}{$\begin{array}{c}\text { Lavene's } \\
\text { Test }\end{array}$} & \multirow[t]{2}{*}{ P Value } \\
\hline & Mean & S.Dev & Mean & S. Dev & & \\
\hline Religiusitas & 5,12 & 0,72 & 5,08 & 0,72 & 0,710 & 0,727 \\
\hline Machiavellian & 4,35 & 1,06 & 4,48 & 1,01 & 0,732 & 0,434 \\
\hline Tax Evasion & 1,46 & 0,48 & 3,22 & 0,76 & $0,000 * *$ & $0,000 * *$ \\
\hline
\end{tabular}

Ket: ** signifikansi $<1 \%$, sumber: data primer diolah 2017

Tabel 11. Hasil Pengujian hipotesis

\begin{tabular}{lc}
\hline \multicolumn{1}{c}{ Hipotesis } & Hasil \\
\hline H3a: terdapat perbedaan tingkat religiusitas berdasarakan gender & Ditolak \\
H3b: terdapat perbedaan tingkat machiavellian berdasarkan gender & Ditolak \\
H3c: terdapat perbedaan tingkat tax evasion berdasarkan gender & Diterima \\
\hline
\end{tabular}

Berdasarkan hasil pengujian menggunakan independent sample $\mathrm{t}$ test (tabel 10) dapat disimpulkan bahwa tidak terdapat perbedaan antara laki-laki dan perempuan pada variabel religiusitas dan machiavellian. Nilai $\mathrm{p}$ value pada variabel religiusitas sebesar $0,727>0,05$ dan $\mathrm{p}$ value pada variabel machiavellian sebesar 0,434 > 0,05 yang berarti $\mathrm{H} 3 \mathrm{a}$ dan $\mathrm{H} 3 \mathrm{~b}$ tidak terbukti. Hasil penelitian ini konsisten dengan temuan Westbrook et al (2011); Rindayati \& Budiarto (2017). Hal ini dapat dijelaskan bahwa persepsi laki-laki dan perempuan tidak banyak berubah baik ketika masa kanakkanak maupun setelah dewasa terutama dari sisi rasionalitas. Sementara laki-laki dan perempuan sama-sama menemukan beberapa tindakan yang sama dalam bersikap (Stedham, Yamamura \& Beekun., 2007; Westbrook et al., 2011).

Nilai $p$ value pada variabel tax evasion sebesar $0,000<0,05$ yang berarti H3c dapat dibuktikan artinya terdapat perbedaan antara persepsi etis tax evasion mahasiswa berdasarkan gender. Hasil riset ini mendukung riset sebelumnya bahwa lakilaki cenderung lebih berani mengambil resiko termasuk melakukan pelanggaran, sebaliknya perempuan cederung lebih berhati-hati dan lebih berperilaku etis (Tang \& Tang, 2010; Musbah, Cowton, \& Tyfa 2016). Selain itu, temuan ini mendukung temuan sebelumnya bahwa penggelapan pajak dan penghindaran pajak lebih banyak dilakukan oleh laki-laki (Dharma et al., 2016).

\section{SIMPULAN}

Berdasarkan hasil analisis data yang dilakukan dapat diambil kesimpulan bahwa religiusitas berpengaruh signifikan terhadap tax evasion, sedangkan machiavellian tidak berpengaruh signifikan terhadap tax evasion. Selain itu pada variabel religiusitas dan machiavellian tidak terdapat perbedaan berdasarkan gender, namun terdapat perbedaann berdasarkan gender pada variabel tax evasion.

Penelitian ini memiliki beberapa keterbatasan yaitu pertama, penelitian ini hanya menggunakan sampel mahasiswa akuntansi di 8 perguruan tiggiswasta diDaerah Istimewa Yogyakarta saran selanjutnya untuk memperluas sampel dapat dilakukan (crooss cultural studies) karena akan menghasilkan berbagai sudut pandang yang menarik (Pope \& Mohdali, 2010). Kedua, penelitian ini tidak masukkan umur responden sebagai dasar analisis. Saran untuk penelitian selanjutnya untuk menggunakan umur karena adanya keterkaitan antara umur dengan religiusitas 
(Parboteeah, Hoegl, \& Cullen, 2008; Walker et al., 2012). Selain itu terdapat perbedaan tingkat machiavellian antara manajer berusia muda dengan manajer yang berusia tua (Ross \& Robertson, 2003). Ketiga, penelitian ini hanya meneliti variabel religiusitas dan machiavellian saran penelitian yang akan datang untuk memasukkan variabel norma dan budaya karena hasil riset sebelumnya menunjukkan bahwa norma dan budaya berhubungan dengan tax morale (Torgler et al., 2008; Hafizhah \& Basri, 2016).

\section{REFERENSI}

Allport, G. W. 1950. The Individual and His Religion. New York: MacMillan

Anderson, G. M., \& Tollison, R. D. 1992. Morality and Monopoly: The Constitutional Political Economy of Religios Rules. Cato J. 12: 373

Arikunto, S. 2013. Prosedur Penelitian Suatu Pendekatan Praktik. PT Rineka Cipta: Jakarta

Aziz, T. I., \& Taman, A. 2015. Pengaruh Love of Money dan Machaivellian terhadap Persepsi Etis Mahasiswa Akuntansi. Junal Nominal. 4 (2): 31-44

Basri, Y. M. 2015. Pengaruh Gender, Religusitas dan Sikap Love of Money pada Persepsi Etika Penggelapan Pajak Mahasiswa Akuntansi. Jurnal Ilmiah Akuntansi dan Bisnis. 10 (1): 45-54

Basri, Y. M., \& Surya, R.A. S. 2014. Pengaruh Keadilan, Norma Ekspektasi, Sanksi dan Religiusitas terhadap Niat dan Ketidakpatuhan Pajak. Akuntabilitas. 7 (3): 162-176

Christie, R., \& Geis, F. 1970. Studies in Machiavellianism. New York: Academic Press

Conroy, S. J., \& Emerson, T. L. 2004. Business Ethics and Religion: Religiosity as a predictor of ethical awareness among atudents. Journal of Business Ethics. 50 (4): 383-396

Dharma, L., Agusti, R., \& Kurnia, P. 2016. Pengaruh Gender, Pemahaman Perpajakan dan Religiusitas terhadap Persepsi Penggelapan Pajak. Jurnal Online Mahasiswa Fakultas Ekonomi Universitas Riau. 3 (1): 1565-1578

Fauzan, F. 2015. Pengaruh Religiuistas dan Ethical Climate terhadap Ethical Behavior. Jurnal Ekonomi Modernisasi. 11 (3): 187-202

Feld, L, P., \& Frey, B, S. 2007. Tax Compliance as The Result of a Psychological Tax Contact: The Role of Incentives and Responsive Regulation. Law \& Policy. 29 (1): 102-120

Ghozali, I. 2011. Analisis Multivariate Program IBM SPSS 19. Semarang: Badan Penerbit Universitas Diponogoro

Glock, C. Y., \& Stark, R. 1965. Religion and Society Intension. Chicago: Rand McNally.

Hafizhah, I., \& Basri, Y, M. 2016. Pegaruh Etika Uang (Money Ethics) terhadap Kecurangan Pajak (Tax Evasion) dengan Religiusitas, Gender, dan Materialisme sebagai Variabel Moderasi. Jurnal Online Mahasiswa Fakultas Ekonomi Uiversitas Riau. 3 (1): 1652-1665

Isroah, I., Hutama, P, S., \& Yusita, A, N. 2016. Persepsi Etika dalam Penggelapan Pajak. Jurnal Pendidikan Akuntans Indonesia, 14 (2): 80-97

Li-Ping Tang, T., Chen, Y.-J., \& Sutarso, T. 2008. Bad Apples in Bad (Business) Barrels: The Love of Money, Machiavellianism, Risk Tolerance, and Unethical Behavior. Management Decision. 46 (2): 243-263

Longenecker, J, G., McKnney, J, A., \& 
Moore, C, W. 2004. Religious Intensity, Evangelical Christianity, and Businnes Ethics: An Empirical Study. Journal of Business Ethics. 55 (4): $371-384$

Kurniawati, M., \& Toly, A. A. 2015. Analisis Keadilan Pajak, Biaya Kepatuhan, dan Tarif Pajak terhadap Persepsi Wajib Pajak Mengenai Penggelapan Pajak di Surabaya Barat. Tax \& Accounting Review, 4(2): 1-12

Mardiasmo. 2009. Perpajakan. Edisi Revisi. Yogyakarta: Penerbit Andi.

McDaniel, S. W., \& Burnett, J. J. 1990. Consumer Religiosity and Retail Store Evaluative Criteria. Journal of the Academy of Marketing Science, 18(2): 101-112

McGee, R, W., Benk, S., Yildirim, H., \& Kayikci, M. 2011. The Ethics of Tax Evasion: A Study of Turkish Tax Practitioner Opinion. European Journal of Social Sciences. 18 (3): 468-480

McGee, R, W., \& Preobragenskaya, G, G. 2006. The Ethics of Tax Evasion: A Survey of Romanian Business Students and Faculty. Accounting and Financial Systems Reform in Eastern Europe and Asia. 1 (8): 299-334

Mokhlis, S. 2009. Relevancy and Measurement of Relisiosity in consumer Behavior Research. Internasional Business Research. 2 (3): 75

Mulyani, S. 2015. Analisis Pengaruh Jenis Kelamin dan Status Pekerjaan terhadap Persepsi Etis Mahasiswa Akuntansi dengan Love of Money sebagai Variabel Intervening. Majalah Ilmiah Solusi. 14 (3): 1-16

Musbah, A., Cowton, C, J., \& Tyfa, D. 2016. The Role of Individual
Variables, Organizational Variables and Moral Intensity Dimensions in Libyan Management Accountants' Ethical Decision Making. Juornal of Business Ethics. 134 (3): 335-358

Muthmainah, S. 2006. Studi Tentang Perbedaan Evaluasi Etis, Intensi Etis dan Orientasi Etis dilihat dari Gender dan Disiplin Ilmu: Potensi Rekruitment Staf Profesional pada Kantor Akuntan Publik. Simposium Nasional Akuntansi IX. Padang

Parboteeah, K, P., Hoegl, M., \& Cullen, J, B. 2008. Ethics and Religion: An Empirical test of A Multidimensional Model. Journal of Business Ethics. 80 (2): 387-398

Pope, J., \& Mohdali, R. 2010. The Role of Religiosity in Tax Morale and Tax Compliance. Austl. Tax F. 25: 565596

Richmond, K, A. 2001. Ethical Reasoning, Machiavellian Behavior and Gender: The Impact on Accounting Students' Ethical Decision Making. Dissertation. Virginia Polytechnic Institute and State University

Rindayati, R \& Budiarto, D, S. 2017. Hubungan antara Love of Money, Machiavellian dengan Persepsi Etis: Analisis Berdasarkan Perspektif Gender. Akuntabilitas. 10 (2): 239248

Rosianti, C \& Mangoting, Y. 2015. Pengaruh Money Ethics terhadap Tax Evasion dengan Intrinsic dan Extrinsic Religiosity sebagai Variabel Moderating. Tax \& Accounting Review. 4 (1): 1-11

Ross, W, T \& Robertson, D, C. 2003. A Typology of Situational Factors: Impact on Salesperson DecisionMaking About Ethical Issues. Journal of Business Ethics. 46 (3): 213-234 
Sekaran, U., \& R. J. Bougie. 2016. Research Method for Business: A Skill-Building Approach. 7th edition, Wiley \& Son.

Shafer, W. E., \& Simmons, R. S. 2008. Social Responsibility, Machiavellianism and Tax Avoidance: A study of Hong Kong Tax Professionals. Accounting, Auditing \& Accountability Journal. 21(5): 695-720.

Sharma, M. K., \& R. Bhagwat. 2006. Performance Measurements in the Implementation of Information Systems in Small and Medium Sized Enterprises: A Framework and Empirical Analysis. Measuring Business Excellence, 10 (4): 8-21.

Singhapakdi, A., Vitell, S.J., Lee, D,-J., Nisius, A. M., \& Grace, B, Y. 2013. The Influence of the Love of Money and Religiosity on Ethical DecisionMaking in Marketing. Journal of Bussines Ethics, 114(1): 183-191

Stedham, Y., Yamamura, J, H \& Beekun, R, I. 2007. Gender Differences in Business Ethics: Justice and Relativist Perspectives. Business Ethics: A European Review. 16 (2): 163-174

Sugiono. 2010. Metode Penelitian Kuantitatif, Kuaitatif dan $R \& D$. Bandung: Alfabeta.

Tang, T, L-P \& Chen, Y,-J. 2008. Intelligence vs. Wisdom: The Love of Money, Machiavellianism, and Unethical Behavior Accross College Major and Gender. Journal of Business Ethis. 82 (1): $1-26$

Tang, T, L-P \& Tang, T, L-N. 2010. Finding the Lost Sheep: A Panel Study of Business Students' Intrinsic Religiosity, Machiavellianism, and Unethical Behavior Intentions. Ethics \& Behavior. 20 (5): 352-379

Torgler, B., Demir, I, C., Macintyre, A.,
\& Schaffner, M. 2008. Causes and Consequences of Tax Morale: An Empirical Investigation. Economic Analysis and Policy. 38 (2): 313-339

Utama, A., \& Wahyudi, D. 2016. Pengaruh Religiusitas terhadap Perilaku Kepatuhan Wajib Pajak Orang Pribadi di Provinsi DKI Jakarta. Jurnar Lingkar Widyaiswara. 3 (2): 1-13

Vitell, SJ, Keith, M., \& mathur, M. 2011. Antecedents to the Justification of Norm Violating Behavior among Business Practitioners. Journal of Bussines Ethics. 101: 163-173

Walker, A,G., Smither, J, W., \& DeBode, J. 2012. The Effects of Religiosity on Ethical Judgement. Journal of Business Ethics. 106 (4): 437-452

Wati, M., \& Sudibyo, B. 2016. Pengaruh Pendidikan Etika Bisnis dan Religiusitas terhadap Persepsi Etis Mahasiswa Akuntansi. Jurnal Economia. 12 (2): 183-201

Westbrook, K, W., Steven Arendall, C., \& Padelford, W, M. 2011. Gender, Competitiveness, and Unethical Negotiation Stategies. Gender in Management: An International Journal. 26 (4): 289-310

Yelshinta, R \& Fuad, F. 2013. Love of Money, Ethical Reasoning, Machiavellian, Questionable Actions: The Impact on Accounting Students' Ethical Decision Making by Gender Moderation. Diponegoro Jurnal of Accounting. 2 (3): 731-723

Yuliana \& Cahyonowati, N. 2012. Analisis Pengaruh Persepsi Pentingnya Etika dan Tanggung Jawab Sosial, Sifat Machiavellian, dan Keputusan Etis terhadap Niat Berpartisipasi dalam Penghidaran Pajak. Diponegoro Journal of Accounting. 1 (1): 1-13

Zain, M. 2008. Manajemen Perpajakan. Jakarta: Salemba Empat. 